\title{
Artificial Intelligence and Contracts: A New Reality
}

\section{Da Silva Giannakos DB*}

Lawyer and Master and doctoral student in law, UNISINOS, Brazil

*Corresponding author: Demétrio Beck da Silva Giannakos, Lawyer and Master and doctoral student in law, UNISINOS, Brazil, Tel: 51999935312; Email: demetrio@giannakos.com.br

Opinion

Volume 4 Issue 2

Received Date: May 01, 2021

Published Date: May 13, 2021

DOI: $10.23880 /$ abca-16000182
This article suggests new changes brought about by artificial intelligence in Law, especially with regard to private relations. Thus, it is believed that artificial intelligence, in this sense, can facilitate the control and fulfillment of the contractual obligations of the parties involved.

Over time, the idea of technology has gained new outlines and specifications and currently involves an extensive network of researchers and interdisciplinary projects. With this in mind, the notion of technology is broad and can be addressed from different perspectives. We live in a totally virtual world. Many of the activities previously carried out solely and exclusively by humans have either been completely replaced by the machine or may already have some type of technological mechanism that helps human activity.

AI is already fully inserted into everyone's daily life, even from public bodies as tools to analyze decision making by citizens and as a way of assigning public resources to the most deprived areas of the State. In other words, today it can be said that decisions are made based on the data collected and, for this decision making, the AI becomes crucial as a support tool and suggestion on how to make the decision.

For Javier Echeverría, "the main objective of techno science, in exchange, is to transform the world, whether natural, social or artificial". And, certainly, it can be said that the current world is already very different from what we lived about ten years ago. Today, in all spheres (whether public or private), technology is present to assist or even to effect some service or decision making.

With regard to today's professions, technology also plays a key role. Today, there are new professions, precisely to manage these new technologies, as obsolete professions, which were practically extinguished with technological advances in some areas. As for the Law, no matter how complex it is, the tendency is for artificial intelligence to bring, in a way, automation of notary procedures and innovation. Automation in the sense that some activities that were previously carried out by employees and interns will now be performed by artificial intelligence and innovation by changing the paradigm in the way these activities were previously carried out.

In the Brazilian legal system, for example, much has been debated about the use of artificial intelligence in the judicial process, as a way to assist the judge in decision-making and even in decision-making itself. However, little has been debated (yet) about the use of AI in contractual matters.

In a capitalist system, which recognizes the principle of freedom of private initiative as its key point, economic operators (parties to the contract) are free to give their contracts the concrete contents they deem most desirable, as well as to change them later to readjust them to the different and often unpredictable economic and social scenarios they are experiencing. The contractual regulation is thus the result of the parties' agreed will, constituting the point of confluence and balance between interests - normally opposed.

The great distinction of the contract for any other mechanized phenomenon is the existence of a high degree of freedom on the part of the contractors. In the words of Ian Macneil: "Contract is the projection of exchange into the future, a projection emanating from a combining in a social matrix (...)".

It was from reading a recent article published by Gustavo Tepedino and Rodrigo da Guia Silva that the inspiration to debate a little more about this topic arose. For the authors, AI could be used as a price fixing instrument, providing 
flexibility to contracts, in order to reduce the transaction costs of contracts as a result of eventual supervening facts. AI could be used as a way of controlling automatic adaptation clauses, in which the clause establishes the seller's right to revise the price originally set if the costs of inputs exceed a certain level of a given Stock Exchange.

It would be the case of so-called smart contracts. It is a form of contracting in which execution is automated - not automatic -, that is, through systems whose operation is determined by algorithms. The term smart comes from the fact that contractual execution takes place without human intervention; the settlement of the contract is triggered automatically if the pre-agreed conditions codified in the contract are met. However, it is important to note that smart contracts do not necessarily use AI, as stated by Ana Taveira da Fonseca: "Just by name, these contracts are not smart, since this technology does not necessarily have any artificial intelligence mechanism that to make autonomous decisions for which it was not initially programmed".

The example mentioned above, for by itself, it would help a lot in cases of lease contracts, in which they are often fixed based on the value of the soybean grain. In other cases, such as lease agreements, there may be a limit setting for the monetary correction, so that the lessee is not unduly harmed. In the case of the use of this technology in contracts, it is believed that the respect for the terms fixed in the contracts would be even greater.

Let's go to a hypothetical case. Today, in the city of Paso Fundo/RS, $60 \mathrm{~kg}$ of soy is worth approximately R $\$ 160.00$. If a farmer A, from Paso Fundo/RS, signed a lease with his tenant $B$ and, in its clauses, there was a resolutive clause that, if the price of soy in the region exceeds the value of $R \$ 180.00$ every $60 \mathrm{~kg}$ the contract would be automatically terminated, using a certain algorithm.

In the case of lease contracts, for example, in October 2020 , information was already published on the need to readjust the lease contracts in which the readjustments were foreseen based on the IGPM index. With the rise of the IGPM, the lease contracts (residential or commercial) that will complete twelve months of validity will soon have a significant adjustment, which has not been observed since the time of the Real Plan. All of this at a time when the country is going through a crisis in the face of the Covid-19 pandemic. Hypothetically, if an algorithm were used in these contracts to limit the readjustment to a certain index, there would not even be a need for readjustment between the parties. AI would do it automatically. Without the use of such technology, there is room for use by one of the parties of the theory of excessive burdens. This theory has its origins precisely in objective good faith. In other words, the parties would establish, in advance, a mechanism for the automatic termination of the contract, so as not to depend on any opportunistic behavior by one of the parties.

The advantages of using this technology are many. However, perhaps the most important is precisely not filing a lawsuit. Stephen Holmes and Cass R. Sunstein, in their work The Cost of Rights, identified very well one of the causes for the overcrowding of the Judiciary in lawsuits: "A classic maxim of legal science says that 'there is no right without the corresponding legal remedy".

The use of artificial intelligence may well diminish the search for the Judiciary, with a view to mitigating cases of contractual non-compliance. 